Research Article

\title{
Investing in Renewable Energy and Energy Efficiency in Palestinian Territories: Barriers and Opportunities
}

\author{
Aysar Yasin ${ }^{(D},{ }^{1}$ Cecilia Camporeale, ${ }^{2}$ Mohammed Alsayed, ${ }^{3}$ Roberto Del Ciello, ${ }^{2}$ \\ and Basel Yaseen ${ }^{4}$ \\ ${ }^{1}$ Energy Research Center, An-Najah National University Nablus, P.O. Box:7, State of Palestine \\ ${ }^{2}$ ENEA, Department of Sustainability, Rome, Italy \\ ${ }^{3}$ Energy Engineering and Environment Department, An-Najah National University Nablus, P.O. Box:7, State of Palestine \\ ${ }^{4}$ Palestinian Energy and Environment Research Center, Al Irsal Str. Al Masayef, Ramallah, State of Palestine
}

Correspondence should be addressed to Aysar Yasin; aysar.yasin@najah.edu

Received 1 August 2021; Revised 21 October 2021; Accepted 1 November 2021; Published 17 November 2021

Academic Editor: Alberto Álvarez-Gallegos

Copyright (c) 2021 Aysar Yasin et al. This is an open access article distributed under the Creative Commons Attribution License, which permits unrestricted use, distribution, and reproduction in any medium, provided the original work is properly cited.

The main objective of this paper is to identify the renewable energy (RE) and energy efficiency (EE) policy and regulatory risks and barriers in the Palestinian Territories (PT). An accurate insight into the market structure and normative frameworks for RE and $\mathrm{EE}$ investments in the PT is performed. For this purpose, a survey has been conducted through two questionnaires and interviews addressed to public decision-makers and local and foreign sectoral companies to study the market confidence in the field of renewable energy sources (RES) and EE. The questionnaire was designed to investigate the attractiveness of RE and EE in the country by directly involving the various market players and to identify what could encourage or hinder investment. RE and EE are, in fact, a valid response to the needs of the PT to guarantee independence and security of supply, ensure access to energy throughout the territory, and reduce emissions. The climate-related issues are listed in the Palestinian political agenda. National subsidies and grants are offered for investment in RES and EE but are still the main barriers. Developments towards further utilization of RES are in progress continually. Marketing campaigns are stimulating the production of RE and EE promotion. RES and EE laws and regulations are continually issued.

\section{Introduction}

The energy sector is a key input for countries' economic development [1]; it affects all aspects of the society. It would be very hard to imagine modern societies without a secure supply of electricity [2], but at the same time, fossil fuel combustion is the largest human influence on climate, accounting for $80 \%$ of anthropogenic greenhouse gas (GHG) emissions [3-5], causing one of the biggest challenges of the twenty-first century $[1,3,6]$.

To reduce the impact of GHG emissions and avoid the consequences of the expected $+2^{\circ}$ Celsius threshold which represents the arbitrary threshold set by the international community as a tolerable level of warming [7], it is necessary to realize the decarbonization of energy sector $[8,9]$. Any failure in this target means the continued increase in GHG emissions will lead to negative environmental implications that will affect all living beings, including humans, particularly those who live in low-income societies [10].

Even if Miller et al. [9] argue that "the future of energy systems is one of the central policy challenges facing industrial countries," we suggest a large extension of this sentence, because the energy system or better the accessibility or availability of energy will be more central issues for both industrial and emerging countries, with possible important impacts also to energy infrastructure [1].

Investing in $\mathrm{RE}$ and $\mathrm{EE}$ is the strategic solution to guarantee energy availability at low prices $[11,12]$ and, simultaneously, to ensure that emission threshold level will be in line with the objective of the United Nations Framework 
Convention on Climate Change (UNFCCC) to stabilize GHG emissions at a level that prevents dangerous anthropogenic consequences on the global climate system [13]. RES can be a solution for a transition to a more sustainable economy and helps to achieve economic stability, especially for countries affected by the volatility of oil prices [11, 14]. For all those reasons, aiming at RES means obtaining double benefits: on one hand, to assure sustainable economic growth [10] and on the other hand to realize a fully clean energy transition towards a sustainable system [15].

Despite the great potential and need to use RES and EE for solving energy-related environmental challenges, improving population health, education, and lifestyles, there is a strong link between income levels and energy investment: nearly 90\% of energy investment in 2018 was concentrated in highand upper-middle-income countries and regions [16].

Several barriers could impede the penetration of $\mathrm{EE}$ and $\mathrm{RE}$ technologies. Aiming for sustainable development requires identifying and overcoming these barriers. As International Energy Agency (IEA) declared "to meet sustainable development goals, more investment is needed in the regions that face the highest economic and financial constraints" [16].

This paper is based on the MeetMED Investment Country Report on RE and EE carried out within the framework of the EU-funded project "Mitigation Enabling Energy Transition in the Mediterranean Region" (MeetMED) and focuses on mapping the investment climate to mitigate the investment risks for EE and RES technologies in the PT. The main objective is to identify the policy and regulatory risks and barriers by gathering updated information from key market players on the investment climate, after an overview of the energy market structure and the legislative framework for investments in the field of EE and RES.

Although previous contributions discussed incentives, obstacles, opportunities, and challenges for the Palestinian sector in general, most of it focused on one field, either EE or RE, and the achieved results were based on the author's judgmental knowledge and published data only. It did not dig deeply to present a detailed comprehensive analysis, and in most situations, it ignored legislative and energy policy effects.

The availability of data and statistics is of great significance to evaluate and assess the energy demand, clean energy, and sustainable energy development strategies. Studies and analyses with simulation models to forecast energy demand trends and how to cover them (i.e., RE vs. fossil fuel) are important. They offer useful information and support tools for policy and decision-makers and energyexperts in sustainable energy planning [17].

More studies and complex investigations are required on RE potential and energy consumption, access to electricity, energy dependency, and $\mathrm{CO}_{2}$ emissions [18] concerning the specific characteristics of the country under analysis. In the same context, the relations between governance indicators and green growth should be analyzed in detail of each country's reality to contribute to the achievement of environmental sustainability goals $[19,20]$.

This article discusses the investment climate of RES and EE in PT. It provides a transparent and comprehensive anal- ysis of the legal and regulatory framework, electricity, market and institutional structure, EE, RE, and foreign investment legislation. It shed the light on the country's information, political system, economic situation, national financial institutions, and international investment flows. It describes the significance of the energy sector on the national economy, energy supply and consumption, national energy plan, and strategy. To do so, the PT market confidence in the RES had been analyzed using two questionnaires. The first one is directed at public authorities on FDI attractiveness in RES. The stockholder's list includes PERC, Ministry of Finance and Planning, Ministry of National Economy/Standards and Metrology Association, Environment Quality Authority (EQA), DisCos, Palestinian solar and sustainable energy society, PIPA, and PETL. The second questionnaire is directed to entrepreneurs/companies potentially interested in investing in RES in the PT. The results of this research will highlight investment risks and barriers, taking into account the experience of domestic and foreign market players. In addition, it will provide a deep knowledge that will enable promoting energy investment through identifying potential opportunities and recommending new policies.

The remaining parts of this article are organized as follows: Section 2 presents the country's background and literature review. Section 3 presents the method and data, while Section 4 provides the results and discussion. Finally, Section 5 reports the main conclusions and recommendations.

\section{Country Background and Literature Review}

PT includes two land areas: the West Bank $5949 \mathrm{~km}^{2}$ (including East Jerusalem) and the Gaza Strip $365 \mathrm{~km}^{2}$ [21]. The population according to census 2017 [22] is 4.78 million inhabitants for an area of $6020 \mathrm{~km}^{2}$ with a population density of 484 and 5203 people $/ \mathrm{km}^{2}$ in the West Bank and Gaza Strip, respectively. It is worth noting that population density in the Gaza Strip is among the highest population densities in the world [22]. PT is divided into three administrative regions: Areas A, B, and C. In Area A, the full civil and security control belong to PT. In Area B, PT has civil control, but security control is a joint between Israel and PT. In Area C, full civilian and security control are provided by Israel. Approximately $60 \%$ of the land regions in the West Bank are classified as Area C [23].

The PT is a very complex area with a fragile and unclear political situation reflected in the slowdown of the economic performance of recent years. The GDP is different in the two administrative territories: West Bank and Gaza Strip. In 2017, the GDP in PT grew by 3.1\%; the GDP per capita in the West Bank increased by $2.4 \%$, whereas it declined by $2.9 \%$ in Gaza Strip [24].

Also, the different situation limits the potential development of infrastructures and the development and implementation of policies related to the energy sector: the energy situation is severe in the Gaza Strip, and it is improving in the West Bank. This complex energy situation is due to the substantial dependence of Palestinians on Israel; the physical separation of Gaza and West Bank, energy sources, and the 
associated high costs are the driving force for finding alternative sources. RE and EE are the most promising solutions to the problem of the energy crisis in PT. In 2018, oil and gas represented about $58 \%$ of the total national balance; imported and generated electricity is about $28 \%$, and RE (solar energy, wood, etc.) is about 12\% [25].

The electricity supply meets only half of the demand in Gaza, which leads to frequent blackouts. Although the West Bank generally has around-the-clock electric power, a deficiency appears during winter and summer. PT relies primarily on its electricity needs on the import flow from Israel, Egypt, and Jordan; however, the costs of energy are higher than in neighbouring countries [26].

Since 2010, PENRA has embarked on a comprehensive program for restructuring and developing the energy sector, including the legal, legislative, regulative, and institutional aspects within a clear strategic vision. In 2012, the Palestinian cabinet adopted the overall RE strategy [27] that set a target of $130 \mathrm{MW}$ from different RES for electricity generation by 2020 .

In 2012, an initiative launched by PENRA called PSI is established. Under the PSI plan, households' owners purchased the solar systems from developers or installers, possibly through "green loans" and then sell energy produced back to the grid in return for a FIT.

PENRA set out a sectoral energy strategic framework for developing the energy sector for the period 2017-2022. It takes into account the new agreements with Israel regarding the transfer of energy distribution sector to the Palestinian government; the government plans to exploit and develop oil and natural gas in PT, the supply of the Gaza Strip with natural gas, and the legislation for the development and the exploitation of RES.

The overall national strategy of the sector is to build an integrated Palestinian energy sector that achieves the concept of sustainability and continuity of development. It also provides energy demand by raising the percentage of clean energy in the total energy supplied to the market and by reducing the negative environmental impacts of energy supply and consumption in addition to the production and the consumption of energy as efficiently as possible, while ensuring the realization of the concept of security of energy supply, which is essential to achieve the principle of sustainability of the sector [27].

There are few papers and reports that shed the light on the opportunities and challenges of the RE and EE in PT. This report [28] discussed the opportunities and challenges of developments in Palestinian rural areas. In reference [29], the authors analyzed the opportunities and challenges of RE in PT. Specifically, it discussed the energy situation and assessed the potential of RE in the PT. In [30], the researchers discussed promises for decreasing the importation of energy sources from neighboring countries. The paper concluded that there is a great potential to invest in RE and EE. In [31], the authors assessed the potential of solar energy in the Gaza Strip in PT and concluded that solar energy can strongly reduce the dependency on conventional energy. The report securing energy for development in PT [32], published by the World Bank, analyzes accurately the energy situation in PT and the potential for further utilization of RE. In [33], an RE assessment study is implemented and sponsored by PENRA aimed to assess the potential of REs in the PT. PIPA published a report in 2020 [34] showing the reasons and motivations behind investing in PT in the RE sector in PT. The report discussed the incentives, success stories, and PT's obligation to investors. In 2016, the World Bank, PENRA, and AFD prepared a national energy efficiency action plan for 2020-2030 [35]. The National Energy Efficiency Action Plan (NEEAP) introduces more ambitious EE goals.

\section{Research Methodology}

As mentioned before, attracting investment is crucial for achieving sustainability and the respect of the international commitments to fight climate change (i.e., Paris Agreement). To do this, it is necessary to discuss and involve relevant stakeholders in identifying those hurdles that impede stable growth.

The best tool to have a broader point of view is by conducting exploratory surveys, with the main purpose of framing the economic and institutional context in which companies and potential investors are aiming to invest in RES and EE, both considering the relevant barriers and areas of excellence.

In this research, the confidence in the EE and RES markets in the PT had been analyzed using two questionnaires and interviews that targeted two different stakeholders: local public authorities and Palestinian and foreign companies interested in RES and EE investments.

The first questionnaire targeted public authorities and is aimed at studying the FDI attractiveness in RES and EE. This questionnaire research questions that are intended to be answered are as follows:

(i) Do climate-related issues receive growing attention on the Palestinian political agenda?

(ii) Do financial incentives for RES and EE exist?

(iii) Are the standardization, licensing, and planning regulated for both small- and large-scale RE producers?

(iv) Is the local market mature for electricity production and consumption?

(v) Do marketing campaigns promote the production of RE in PT?

(vi) Are required related technical expertise and advice available?

Table 1 shows clearly how the data was collected, how many questionnaires were sent and how many were received, and who were the respondents.

The second questionnaire targeted entrepreneurs/companies potentially interested in investing in PT on RES and EE. The method used for conducting the questionnaires is Google link, personal interview, email, and telephone call. Thirty questionnaires were sent, and twenty-five were received. The companies preferred their names to be confidential.

The research questions that are intended to be answered are as follows: 
TABLE 1: Questionnaire directed on public authorities on FDI attractiveness in RES and EE.

Number of sent questionnaires

Number of received questionnaires

Method of collection

Sample segments and number of filled questionnaires per segment

\section{3}

27

Google link, personal interview, email, and telephone calls

Experts and consultants in RE and EE 6

Ministry of National Economy

Standards and Metrology Association

EQA

DisCos

Palestinian solar and sustainable energy society

PIPA

PETL

PERC

Ministry of Finance and Planning (i) Is the technological scope of the local enterprises related to $\mathrm{PV}$ and $\mathrm{SWH}$ ?

(ii) What is the range of revenues and assets of local enterprises working in the field of RE?

(iii) Are suppliers of RE and $\mathrm{EE}$ equipment both national and international?

(iv) Where is the investment in RE concentrated?

(v) Are economic and financial barriers significant for the promotion of the RE?

(vi) Are technological and infrastructural barriers significant for the promotion of the RE?

(vii) Are institutional and regulatory barriers significant for the promotion of the RE?

(viii) Are public awareness and information barriers significant for the promotion of the RE?

For the data analysis and the research question investigation, the researchers followed a simple approach. Cross tabulation, frequency, and percentage demonstration are used to understand and discuss the RE and EE barriers and opportunities.

\section{Results and Discussions}

As introduced in the research methodology, to study the market confidence in the field of RE and EE, two questionnaires were conducted with two different target groups.

4.1. Questionnaire for Public Authorities on FDI Attractiveness in RE and EE. A questionnaire for public authorities on FDI to assess the effectiveness and adequacy of national and local policies to increase FDI in RES and/ or EE was conducted. The target group of this questionnaire was the following institutions and corporations:

(i) PENRA, PERC, PEC, PETL, PIPA, PIF, SUNREF, and EQA (ii) Private and nonprivate research centers in the field of energy and Palestinian solar and sustainable energy society

(iii) Academic institutions represented by professors specialized in the field of RES and EE and working as consultants: An Najah University, Birzeit University, and Palestinian Polytechnic University

To test the scientific assumptions related to the government institutions' point of view about investments in RES and EE, the following items were invoked in the questionnaire.

4.1.1. Climate Governance. Table 2 summarizes the responses of the public authorities about climate governance. A large proportion of surveyed sample indicated that climate-related issues are a scheduled item in the political agenda. And international corporations resulted in several related projects.

4.1.2. Financial Incentives for RES and EE. Table 3 summarizes the responses of the public authorities about the financial incentives for RES and EE.

4.1.3. Standardization, Licensing, and Planning. Table 4 summarizes the responses of public authorities about standardization, licensing, and planning.

4.1.4. The Market for Electricity Production. Table 5 summarizes the responses of the public authorities about the market for electricity production.

4.1.5. Electricity Consumption. Table 6 summarizes the responses of public authorities about energy consumption.

4.1.6. Promotion and Information. Table 7 summarizes the answers of public institutions about promotion and information.

4.2. Survey for Entrepreneur/Company Potentially Interested in Investment in PT on RES and EE. The target group of this questionnaire is private companies working in the field of 
TABLE 2: Summarization of answers of public institutions to questions related to climate governance.

Are climate-related issues a scheduled political agenda item?

Into which governance mechanisms are climate-related issues integrated?

Is there any bilateral or multilateral cooperation agreement on climate change mitigation action in PT?

What kind of project is being implemented under such international cooperation? (i) $80 \%$ : agree

The answers are summarized as follows:

(i) In 2010, PENRA conducted an RES assessment in PT

(ii) PENRA has started an awareness campaign by initiating the PSI

(iii) The overall renewable strategy has been adopted with the main target to reach $130 \mathrm{MW}$ or at least $240 \mathrm{GWh}$ by 2020

(iv) In 2015, the RES and EE laws have been ratified by the president of PT in addition to bylaws, such as net metering mechanisms, direct offers, and competitive biddings

(v) NEEAP is aimed at reducing $384 \mathrm{GWh}$ of total energy demand by 2020

(vi) PT recently completed its Initial National Communication Report (INCR)

(vii) PT developed its National Adaptation Plan (NAP)

(i) EU, Sweden, Belgium, and France in the field of RE and EE

(i) The EE program is one of the strategic programs that PENRA has developed with PEC and AFD to participate in the reduction of PNA's expenses

(ii) SUNREF, the project is built on 3 axes cofinanced by AFD and the EU. AFD sponsored the initiative with $€ 25$ million, and the EU sponsored $€ 8$ million

TABLE 3: Summarization of answers of public institutions to questions related to financial incentives for RES and EE.

Are national subsidies and grants available for investments in RES and EE?

Is clear information on financial support readily available?

Is credit at a low interest rate readily available to support RES production and EE implementation?

Are tax reliefs offered to renewable energy producers?

If available, are these favorable financial conditions open to FDI, and under what conditions?

Are guaranteed feed-in tariffs set to encourage RES and EE?

If yes, how high are these tariffs? Are they guaranteed for a certain period (how long)?

Further comments. Please comment on the overall financial framework, the stability/predictability of the policies, and refer to any further issues you consider important. (i) $100 \%$ : yes

(i) $80 \%$ : no

(i) Some local banks manage green funds with soft loans. Those loans with low interest encourage investment in renewable energy and EE

(i) There is a tax exemption offered to RES and EE goods by the Ministry of Finance

(i) These exemptions are applied to FDI if it is registered as a local company

(i) $100 \%$ : yes.

(i) The FIT mechanism does not exist in PT. The only FIT is applied under PSI for the residential sector up to $5 \mathrm{~kW}$ (FIT $0.54 \mathrm{NIS} / \mathrm{kWh}$ )

(ii) This FIT is guaranteed for the lifetime of the system, which is normally 20 years

(iii) The available mechanisms are according to net metering or direct offers through PPA

(i) For a large power station with a capacity above $1 \mathrm{MW}$, the PPA is signed between the developer and PETL as a purchaser and guarantee side

(ii) Some investors are conservative from the PETL guarantee, and they are demanding the sovereignty guarantee. The sovereignty guarantee is a pledge and commitment from the Ministry of Finance to investors or developers in the case DisCos do not commit to paying the cost of energy to an investor

(iii) For power stations with a capacity of less than $1 \mathrm{MW}$, PPA was left to the DisCos and municipalities and village councils
RE. More than 20 surveys were distributed. To have a deep understanding of the domestic enterprises in the West Bank, the following points summarize the answer to the questions and inquiries submitted to the stakeholders either through a questionnaire or direct interview.
The questionnaire pays special attention to factors, such as the following:

(i) The companies working in the field of renewable energy and energy efficiency 
TABLE 4: Summarization of answers of public institutions to questions related to standardization, licensing, and planning for RES and EE.

Is grid connection regulated and facilitated? Is the procedure complicated for small-scale producers?

How is transmission access regulated and facilitated? Is the procedure complicated for small-scale producers?

Is licensing simple and speedy, e.g., through one-stop shops? Are building codes in place to promote renewables, e.g., solar panels on rooftops?

Are renewable energy equipment characteristics sufficiently standardized?
$100 \%$ of questioned institutions agree that:

(i) There is a regulated grid connection, but further facilitations are required

(ii) The procedure for small-scale producers is not complicated but requires further modifications

(i) The transmission access to RE power stations is regulated and facilitated for small- and large-scale producers

(ii) Some power stations are connected directly to LV power lines or MV power lines through a step-up transformer

(iii) All questioned stakeholders confirm that the administrative framework facilitates small renewable energy producers, but some of them need further documents and clarifications

(i) $100 \%$ of the questioned stakeholders agree that the licensing procedure is simple and speedy

(i) Building code in PT is being designed, but it is still in a draft phase

(ii) Green building code is included in the draft, but it is not compulsory

(i) The RES equipment characteristics are sufficiently standardized especially for PV systems and their accessories

(ii) PENRA and Palestinian Standards Institution prepared technical specifications for PV modules, inverters, controllers, batteries, cables, etc.

(iii) The SWH equipment is standardized, but most of the equipment that reaches the Palestinian market through the Israeli market second-hand does not necessarily comply with Palestinian standards

(iv) Some SWHs are locally manufactured, but no testing facilities exist yet to check the compliance with the Palestinian standards

TABLE 5: Summarization of answers of public institutions to questions related to the market for electricity production.

Are PPAs in place whereby small RE producers have priority in selling the energy they generate?

Is there a guarantee for small producers that their energy would be purchased?

Is competitive bidding for the production of RE usually practiced?

In general, to increase the share of RE, which type of producers should be supported the most: large scale or small scale?

Other comments. Please comment on any questions you feel are important. (i) $100 \%$ : yes

(i) If the PPA is signed, the developers have the priority to sell all the energy they produce, and they have a guarantee from PETL and DisCos

(i) Competitive bedding is not practiced in PT yet

(ii) The International Finance Corporation (IFC) with PENRA is preparing all the documents related to the competitive procedure

(iii) 2020 faced the first phase of competitive bedding up to $30 \mathrm{MW}$

(i) The PPA is in force, and it depends on the capacity

(ii) If the power station capacity is greater than $1 \mathrm{MW}$, the PPA is signed between the developer and PETL

(iii) The PPA is signed between the developer and DisCos or the village council if the capacity is less than $1 \mathrm{MW}$

(i) Large power stations require large land areas, available in Areas B and $\mathrm{C}$, but those areas are under full control of Israelis; thus, a complicated procedure is necessary to implement large power stations

(ii) Small power stations require a small area, which is available on the rooftops and in Areas A, B, and C. The high price of land in PT in general-and particularly in Area A-is another element in favor of small-scale power stations (ii) Overview of the activities, revenues, and assets of the companies working in the field of RE and $\mathrm{EE}$

(iii) The investments made and planned in the production of RE from biomass, wind, PV, and solar thermal (iv) The investments made and planned in EE in buildings, industrial processes, lighting, heating, and air conditioning

(v) Investigate the Main Barriers. Financial and economic, technological and infrastructural, 
TABLE 6: Summarization of the answers of public institutions related to electricity consumption.

Can consumers freely choose among competitive electricity providers?

Can consumers opt to buy electricity from RE if they wish to do so?

Are full life-cycle costs (including environmental externalities and health impacts) reflected in energy prices for all types of energy?

Do you think that electricity prices are transparent, i.e., that consumers understand exactly the subcosts included in the energy price? (i) According to the response of the questioned companies, even if the competitive bidding is still not available in PT, this may represent an effective tool to boost the consumption of electricity from RES

(ii) Once the competitive bidding is applied, the RE producer sells electricity to DisCos upon the competitive price

(i) The power sold from RES producers is injected into the electric network. In most cases, the consumers cannot freely choose among competitive electricity providers and cannot opt to buy electricity from RES, at least at this stage

(i) The full life-cycle costs (including environmental externalities and health impacts) do not reflect energy prices for all types of energy

(i) The electricity prices are not fully transparent, and the consumers do not understand exactly the subcosts included in the energy price

(ii) DisCos sell electric energy to consumers mostly twice the price it buys from IEC. The distribution companies justify this increase in operational costs and taxes

TABLE 7: Summarization of answers of public institutions about promotion and information.

Are there marketing campaigns promoting the production of $\mathrm{RE}$ and $\mathrm{EE}$ ?

Is technical expertise and advice easy to access if a small producer/consumer wants to start generating RE?

Which public image about RE is conveyed in the press? Please refer to political statements and messages in the media.
80\% agree that there are marketing campaigns for RE and EE promotion

(i) Some mentioned local media through local newspapers and TVs

(ii) Some mentioned PIPA marketing campaigns

(iii) Some mentioned the conferences and workshops organized in the field of energy

(vi) Some mentioned that the marketing campaigns are normally organized by specific sponsored projects (speed, SUNREF, Bank of Palestine, etc.)

(i) $100 \%$ agree that the technical expertise and advice are easy to access for small producers/consumers that want to start generating RE

(ii) Some mentioned that Palestinian engineers still need external support for grid impact assessment

(i) The governmental media through visual, print, and audio partially participate in marketing campaigns for utilizing PV energy

(ii) PIPA always promotes RES incentives through private and governmental media

(iii) $100 \%$ claims that the campaigns are not sufficient
TABLE 8: Introductory information about domestic enterprises working in the field of RE and EE.

\begin{tabular}{ll}
\hline $\begin{array}{l}\text { Is your company part } \\
\text { of a group? }\end{array}$ & $\begin{array}{l}\text { (i) } 66 \% \text { of the questioned enterprises are } \\
\text { not part of a group }\end{array}$ \\
$\begin{array}{ll}\text { Select the activity of } \\
\text { the company }\end{array}$ & $\begin{array}{l}\text { (i) } 100 \% \text { of the questioned enterprises } \\
\text { are service companies (installation } \\
\text { and operation) }\end{array}$ \\
$\begin{array}{ll}\text { Select the scope of } \\
\text { technology }\end{array}$ & $\begin{array}{l}\text { (i) It is RE, mainly PV technology and } \\
\text { SWHs with its main components }\end{array}$ \\
Select the suppliers & (i) $100 \%$ are international \\
Select the suppliers & (i) $50 \%$ are products \\
& (ii) $50 \%$ are components \\
\hline
\end{tabular}

institutional and regulatory, and public awareness and information

(vi) Risk transfer mechanisms (vii) Reasons for the international expansion of the company in the RE and/or EE sector

4.2.1. Introductory Information about the Domestic Enterprises Working in the Field of RE and EE. There are no domestic enterprises working in the field of RE and $\mathrm{EE}$ before the year 2006. Table 8 shows introductory information about domestic enterprises.

Figure 1 shows the revenues and assets of the questioned domestic enterprises working in the field of RE.

Figure 2 shows the classifications of the customers of the questioned domestic enterprises in addition to the number of employees in each category. The questioned enterprises reveal that most of the employees are electrical, mechanical, and energy engineers as well as technicians.

It is good practice to mention that the structure of the PV systems is locally fabricated. Most of the flat SWH collectors are imported from international suppliers with a small percentage fabricated locally or come from the Israeli 


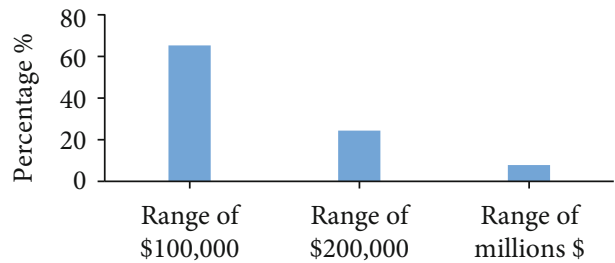

(a)

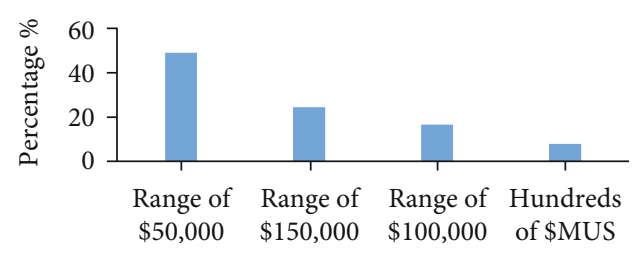

(b)

FIgURE 1: (a) Revenues and (b) assets of the questioned domestic enterprises working in the field of RE.

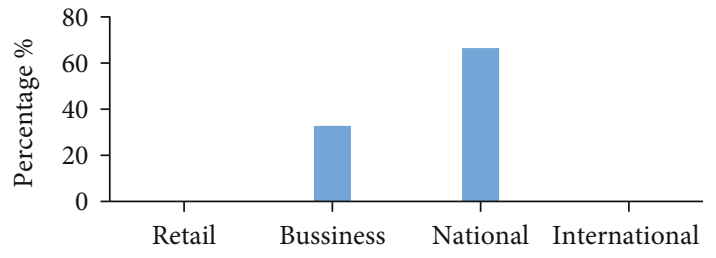

(a)

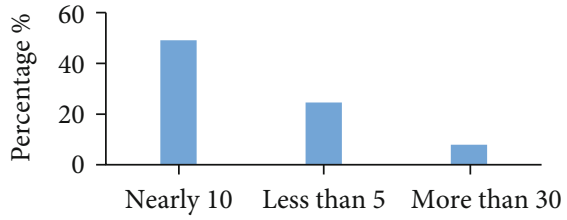

(b)

Figure 2: (a) Classification of the customers and (b) the number of the employees in each category.

TABle 9: Amount of investments in $\mathrm{M} \$$ in $\mathrm{PV}$, wind, biomass, SWH, and EE from 2016 until 2020.

\begin{tabular}{cccccc}
\hline Year & PV & Wind & Biomass & SWH & EE \\
\hline 2016 & 3 & 0 & 0 & 6 & 0 \\
2017 & 16 & 0 & 0 & 7 & 0 \\
2018 & 24 & 0 & 0 & 8 & 0 \\
2019 & 10 & 0 & 0 & 8 & 0 \\
2020 & 72 & 0 & 0 & 8 & 0 \\
\hline
\end{tabular}

All projects and activities related to EE are normally sponsored by projects.

second-hand market. The other components, like structures, storage tanks, pipes, and fittings, are available in the local market. No domestic enterprises working in the field of EE as PENRA performs auditing services in the industrial and commercial sectors in addition to the motivations and supports offered from funded projects.

4.2.2. Investments in Renewable Energy and Energy Efficiency. Table 9 summarizes investments made and planned in PV, SWH, wind, biomass, and EE from 2016 until 2020 according to the interviewed questioned enterprises. The interviewed enterprises reveal that biomass energy is utilized in PT, but just individually and no specialized companies are working in this field.

4.2.3. Barriers to Investments. According to the questionnaire, the barriers to the investment in RES and EE in PT are divided into economic and financial barriers, technological and infrastructural barriers, institutional and regulatory barriers, and public awareness and information barriers. Figure indicates the significance of the economic and financial barriers to the promotion of RE and EE.

Figure 3 indicates the significance of the technological and infrastructural barriers to the promotion of RE.

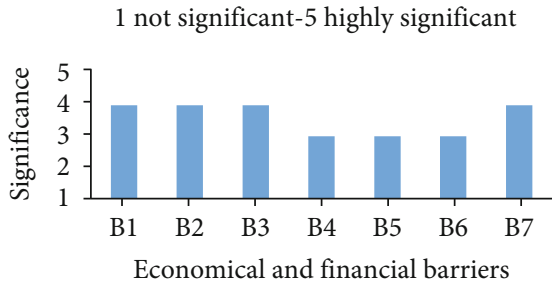

FIgURE 3: Significance of the economic and financial obstacles to the promotion of RE and EE. B1: market design issues, hindering the integration of renewable energies; B2: difficulty in Power Purchase Agreement (PPA) negotiations; B3: unstable prices in the spot market; $\mathrm{B} 4$ : longer economic recovery periods; $\mathrm{B} 5$ : lack of modeling of externalities; B6: limited access to financing; B7: lack of subsidized loans for small or small-scale facilities.

Figure 4 indicates the significance of the institutional and regulatory barriers to the promotion of RE.

Figure 5 indicates the significance of public awareness and information barriers to the promotion of RE.

\section{Conclusion}

The main objective of this paper was to identify the RE and EE policy and regulatory risks and barriers in PT. Future research may be directed towards finding solutions to the barriers and obstacles. The market structure and normative frameworks for RE and EE investments are another objective of the study. The study is limited to the West Bank only, and Gaza Strip was not included.

The main results of the questionnaire for public authorities on FDI attractiveness in RE and EE are summarized in the following. The results include answers to the research assumptions.

(i) The climate-related issues are scheduled in the Palestinian political agenda, and they are integrated 


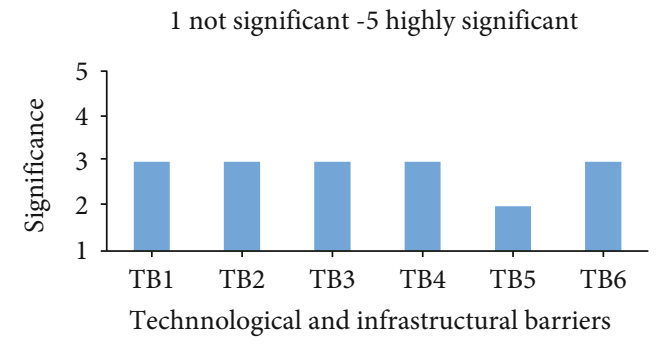

FIgURE 4: Significance of the technological and infrastructural barriers to the promotion of RE. TB1: grid connection constraints and lack of grid capacity; TB2: inadequate infrastructure to accommodate renewables; TB3: long processing time for the large number of permits; TB4: lack of regulatory framework for land securement; TB5: high risk of land speculation due to mining concessions; TB6: lack of coordination among relevant institutions.

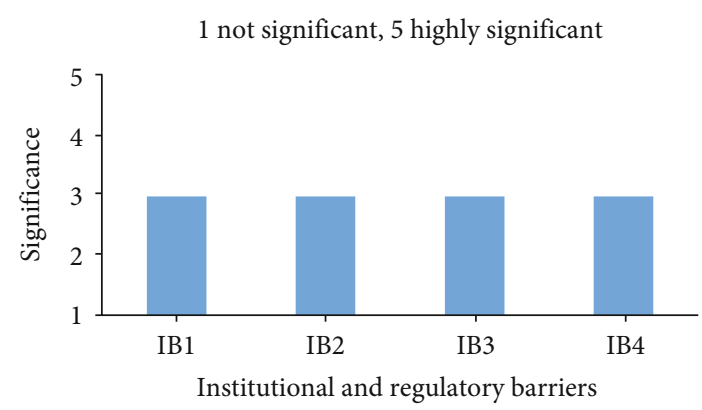

FIGURE 5: Significance of the institutional and regulatory barriers to the promotion of RE. IB1: lack of long-term political strategy on energy; IB2: direct interest and participation of the State in competitive sectors; IB3: lack of a regulatory framework for competition; IB4: lack of coordination among relevant institutions.

1 not significant, 5 highly significant

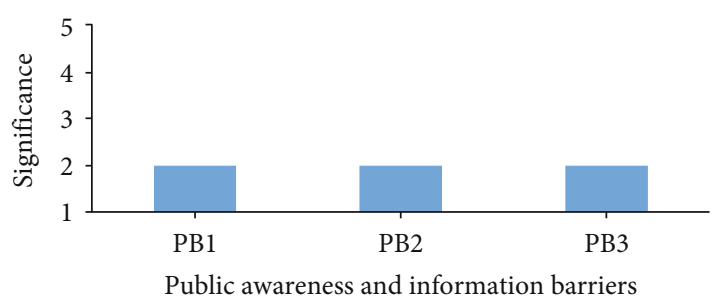

FIGURE 6: Significance of the public awareness and information barriers to the promotion of RE. PB1: local opposition to the development of projects; PB2: lack of dissemination and public awareness; PB3: lack of necessary scientific and technical skills in the workforce.

into governance mechanisms as RES assessment in PT, awareness campaigns, overall RE strategy, RES and EE laws, NEEAP, INCR, and NAP. A bilateral and multilateral cooperation agreement on climate change mitigation action exists in the field of $\mathrm{RE}$ and EE as SPEED and SUNREF projects sponsored by AFD (ii) A large proportion of the surveyed sample indicated that national subsidies and grants are available for investment in RES and EE and that there is clear information related to the readily available financial support. Moreover, $100 \%$ of the surveyed sample agreed that the guaranteed FIT had encouraged the implementation of RES and EE projects

(iii) The procedure for grid connection and transmission access is regulated for small-scale producers but needs further modifications. The RES equipment characteristics are sufficiently standardized

(iv) Some private RES companies complain about the procedure for licensing the PV power systems and connecting them to the grid. Nonetheless, they have a strong tendency to invest in PV electrification

(v) The small-scale RE producers have priority in selling the energy with a guarantee from PETL and DisCos. The competitive bedding is not accomplished in PT yet. The PPA is applicable and is influenced by capacity. The PPA is signed between the developer and DisCos or the village council if the capacity is less than $1 \mathrm{MW}$

(vi) The competitive bidding is still not available in PT. Currently, consumers could not choose the source of electricity. The electricity prices are not transparent, and the consumers do not recognize accurately the subcosts included in the energy price

(vii) Marketing campaigns are stimulating the production of RE and EE promotion. The technical expertise is available and easy to access, but exterior support is essential in grid impact assessment

(viii) DisCos and some stakeholders complain about the possible damage to the electrical equipment due to the bad quality of the power supply injected from some PV power systems. More accurate grid impact assessments should be performed by professional and experienced people

(ix) The accurate review of the laws and regulations issued by PNA and PENRA indicates significant interest from PNA towards further improvement of RES and EE sectors. This is also noted thanks to the activities carried out by PIPA as well as to projects carried out by PIF through investments in school buildings, rooftops, PSI, and others. The government has also established a special regulatory framework favorable to investors

(x) The selling, installing, and maintaining of PV systems is growing, and the commercial feasibility in this sector is increasing due to the increased awareness, promotion, investments, and available projects as well as to reducing the cost of the system over the past few years. This is not true for SWH, even if it is more feasible than PV systems 
(xi) Most of the PV equipment is purchased from Europe and China. The power electronic components are mostly purchased from Europe, while PV modules are mostly purchased from China. The flat plate SWH system collectors are sold from the Israeli second-hand market or locally manufactured, and some are imported from China. The evacuate tube SWH collectors are mainly imported from China

(xii) The lack of subsidized loans for large- or smallscale facilities is one of the obstacles that further investments in the RES and EE are facing. The payback period of PV power stations is not considered an obstacle as it does not exceed 5-6 years

The results and conclusions of the survey for entrepreneurs/companies potentially interested in investment in PT on RES and EE are summarized below. The results include answers to research assumptions.

(i) No domestic enterprises working in the field of RE and EE before the year 2006. The activity of the RE and EE enterprises in PT is specialized in installation and operation. The main scope of RE is $\mathrm{PV}$ and $\mathrm{SWH}$

(ii) About $70 \%$ of the revenues of domestic enterprises working in the field of $\mathrm{RE}$ are in the range of $100,000 \$$, while $50 \%$ of the assets are in the range of $100,000 \$$

(iii) Biomass energy is utilized in PT, but just individually and no specialized companies are working in this field. The amount in investment in PV from 2016 until 2020 is about $135 \mathrm{M} \$$ while it is about $37 \mathrm{M}$ in $\mathrm{SWH}$

(iv) The main barriers of investments in RE and EE are classified into economic, financial, technological, institutional, and regulatory. Figures 3-5 show the significance of each barrier in detail

(v) The study showed that local opposition to the development projects, lack of awareness campaigns, and technical skills are not significant barriers. This is indicated in Figure 6

\section{Nomenclature}

AFD: $\quad$ French Development Agency (Agence française de développement)

DisCos: Distribution companies

EE: $\quad$ Energy efficiency

EQA: Environment Quality Authority

FDI: $\quad$ Foreign Direct Investment

FIT: $\quad$ Feed-in-tariff

GDP: Gross domestic product

GHG: Greenhouse gas

IEC: Israel Electric Corporation

INCR: Initial National Communication Report

PEC: $\quad$ Palestinian Energy and Environment Research Center
PENRA: Palestinian Energy and Natural Resources Authority

PERC: Palestinian Electricity Regulatory Council

PES: $\quad$ Palestinian National Environmental Strategy

PETL: $\quad$ Palestinian Electricity Transmission Company

PIF: $\quad$ Palestine Investment Fund

PIPA: Palestinian Investment Promotion Agency

PNA: Palestinian National Authority

PPA: $\quad$ Power Purchase Agreement

PSI: $\quad$ Palestinian Solar Initiative

PT: $\quad$ Palestinian Territories

RE: $\quad$ Renewable energy

RES: $\quad$ Renewable energy sources

SUNREF: Sustainable Use of Natural Resources and Energy Finance

SPEED: Sustainable Energy Efficiency Development in Palestine

SWH: Solar water heaters.

\section{Data Availability}

The data used to support the findings of this study are included within the article.

\section{Disclosure}

The content of the paper is the sole responsibility of its authors and does not necessarily reflect the views of the EC.

\section{Conflicts of Interest}

The authors declare that they have no conflicts of interest.

\section{Acknowledgments}

This paper depends on some findings of meetMED country report. The report was realized by the Mediterranean Association of the National Agencies for Energy Management (MEDENER) and by the Regional Centre for Renewable Energy and Energy Efficiency (RCREEE), with the participation of ENEA.

\section{References}

[1] J. C. Ciscar and P. Dowling, "Integrated assessment of climate impacts and adaptation in the energy sector," Energy Economics, vol. 46, pp. 531-538, 2014.

[2] IEA, Power Systems in Transition. Challenges and opportunities ahead for electricity security, IEA, Paris, 2020.

[3] T. K. Mideksa and S. Kallbekken, "The impact of climate change on the electricity market: a review," Energy Policy, vol. 38, no. 7, pp. 3579-3585, 2010.

[4] R. Quadrelli and S. Peterson, "The energy-climate challenge: Recent trends in $\mathrm{CO}_{2}$ emissions from fuel combustion," Energy Policy, vol. 35, no. 11, pp. 5938-5952, 2007.

[5] N. Stern, The Stern Review of the Economics of Climate Change, Cambridge University Press, 2007.

[6] W. M. Hanemann, What Is the Economic Cost of Climate Change? Department of Agricultural and Resource, Economics, UC Berkeley, 2008. 
[7] IPCC, Climate Change 2014: Synthesis Report. Contribution of Working Groups I, II and III to the Fifth Assessment Report of the Intergovernmental Panel on Climate Change, IPCC, Geneva, 2014.

[8] P. Denholm, J. C. King, C. F. Kutcher, and P. P. H. Wilson, "Decarbonizing the electric sector: combining renewable and nuclear energy using thermal storage," Energy Policy, vol. 44, pp. 301-311, 2012.

[9] C. A. Miller, A. Iles, and C. F. Jones, "The social dimensions of energy transitions," Science as Culture, vol. 22, no. 2, pp. 135148, 2013.

[10] D. Arent, C. Arndt, M. Miller, F. Tarp, and O. Zinaman, Edited by, the Political Economy of Clean Energy Transitions, a Study Prepared by the United Nations University World Institute for Development Economics Research (UNU-WIDER), Oxford University Press, 2017.

[11] A. Menegaki, "Valuation for renewable energy: a comparative review," Renewable and Sustainable Energy Reviews, vol. 12, no. 9, pp. 2422-2437, 2008.

[12] F. Hvelplund, "Renewable energy and the need for local energy markets," Energy, vol. 31, no. 13, pp. 2293-2302, 2006.

[13] Protocol, Kyoto, Kyoto protocol, UNFCCC Website, 1997, January 2011, http://unfccc.int/kyoto_protocol/items/2830.php.

[14] Y. Krozer, "Cost and benefit of renewable energy in Europe," in World Renewable Energy Congress-Sweden, no. 57pp. 23782384, Linköping University Electronic Press, Linköping; Sweden, 2011.

[15] J. P. Painuly, "Barriers to renewable energy penetration; a framework for analysis," Renewable Energy, vol. 24, no. 1, pp. 73-89, 2001.

[16] IEA, World Energy Investment 2019, IEA, Paris, 2019, https:// www.iea.org/reports/world-energy-investment-2019.

[17] M. Ikram, "Models for predicting non-renewable energy competing with renewable source for sustainable energy development: case of Asia and Oceania region," Global Journal of Flexible Systems Management, pp. 1-28, 2021.

[18] M. Ikram, Q. Zhang, R. Sroufe, and S. Z. A. Shah, “Towards a sustainable environment: the nexus between ISO 14001, renewable energy consumption, access to electricity, agriculture and $\mathrm{CO}_{2}$ emissions in SAARC countries," Sustainable Production and Consumption, vol. 22, pp. 218-230, 2020.

[19] N. Abid, M. Ikram, J. Wu, and M. Ferasso, "Towards environmental sustainability: exploring the nexus among ISO 14001, governance indicators and green economy in Pakistan," Sustainable Production and Consumption, vol. 27, pp. 653-666, 2021.

[20] M. Ikram, Q. Zhang, R. Sroufe, and M. Ferasso, "Contribution of certification bodies and sustainability standards to sustainable development goals: an integrated grey systems approach," Sustainable Production and Consumption, vol. 28, pp. 326345, 2021.

[21] Federal Research Division, Israel a Country Study, Kessinger Publishing, LLC, Paperback edition, 2004.

[22] PCBS, "Populations and establishment census 2017," 2017, http://www.pcbs.gov.ps/Downloads/book2364.pdf.

[23] Israeli-Palestinian Interim Agreement on the West Bank and the Gaza Strip, "From the Knesset website," 1995.

[24] PCBS, "Performance of the Palestinian Economy," 2017, http://www.pcbs.gov.ps.

[25] PCBS, "Energy Balance of Palestine," 2017, http://www.pcbs .gov.ps.
[26] PCBS, "Energy Balance of Palestine," 2018, http://www.pcbs .gov.ps.

[27] "Renewable Energy Strategy in Palestine report," PENRA, 2012.

[28] R. Ghattas et al., "Opportunities and Challenges of Palestinian Development Actions in Area C," Publications of the Applied Research Institute-Jerusalem (ARIJ), 2016.

[29] T. Abu Hamed, H. Flamm, and M. Azraq, "Renewable energy in the Palestinian Territories: Opportunities and challenges," Renewable and Sustainable Energy Reviews, vol. 16, no. 1, pp. 1082-1088, 2012.

[30] M. S. Ismail, M. Moghavvemi, and T. M. I. Mahlia, "Energy trends in Palestinian territories of West Bank and Gaza Strip: possibilities for reducing the reliance on external energy sources," Renewable and Sustainable Energy Reviews, vol. 28, pp. 117-129, 2013.

[31] Y. Fathi Nassar and S. Yassin Alsadi, "Assessment of solar energy potential in Gaza Strip-Palestine," Sustainable Energy Technologies and Assessments, vol. 31, pp. 318-328, 2019.

[32] World Bank Group, "Securing Energy for Development in West Bank and Gaza, summary report," 2017, https://www .un.org/unispal/document/securing-energy-for-developmentin-west-bank-and-gaza-world-bank-report/.

[33] Renewable Energy Resources Assessment in PT, "Report delivered by AF-MERCADOS EMI/Trama Tecnoambiental (TTA)/Interdisciplinary Research Consultant (IDRC) for PENRA," 2011.

[34] Palestinian Investment Promotion Agency, "Why invest in Palestine," 2020, January 2020, http://www.pipa.ps/page .php?Id=1ababey1751742ylababe.

[35] World Bank Group, "West bank \& Gaza energy efficiency action plan in West Bank and Gaza 2020-2030, summary report," 2016, https://documents1.worldbank.org/curated/en/ 851371475046203328/pdf/ACS19044-Replacement-publicfinal-report-p147961-wbgaza-Energy-Efficiency-Action-Plan .pdf. 